\title{
Comprehensive analysis of aberrantly expressed microRNA profiles reveals potential biomarkers of human lung adenocarcinoma progression
}

\author{
JING SUI $^{1}$, RU-SONG YANG ${ }^{2}$, SI-YI XU ${ }^{1}$, YAN-QIU ZHANG ${ }^{1}$, CHENG-YUN LI $^{1}$, \\ SHENG YANG ${ }^{1}$, LI-HONG YIN ${ }^{1}$, YUE-PU PU ${ }^{1}$ and GE-YU LIANG ${ }^{1}$ \\ ${ }^{1}$ Key Laboratory of Environmental Medicine Engineering, Ministry of Education, School of Public Health, \\ Southeast University, Nanjing, Jiangsu 210009; ${ }^{2}$ Department of Thoracic Surgery, \\ Nanjing Chest Hospital, Nanjing, Jiangsu 210029, P.R. China
}

Received February 28, 2017; Accepted July 26, 2017

DOI: $10.3892 /$ or.2017.5880

\begin{abstract}
Lung adenocarcinoma (LUAD) is a complex disease that poses challenges for diagnosis and treatment. The aim of the present study is to investigate LUAD-specific key microRNAs (miRNAs) from large-scale samples in The Cancer Genome Atlas (TCGA) database. We used an integrative computational method to identify LUAD-specific key miRNAs related to TNM stage and lymphatic metastasis from the TCGA database. Twenty-five LUAD-specific key miRNAs (fold change $>2, \mathrm{P}<0.05$ ) from the TCGA database were investigated, and 15 were found to be aberrantly expressed with respect to clinical features. Three miRNAs were correlated with overall survival (log-rank $\mathrm{P}<0.05$ ). Then, 5 miRNAs were randomly selected for verification of expression in 53 LUAD patient tissues using qRT-PCR. Diagnostic value of these above 5 miRNAs was determined by areas under receiver operating characteristic curves (ROC). Finally, the LUAD-related miRNA $m i R-30 a-3 p$ was selected for verification of biologic function in A549 cells. The results of tests for cell proliferation, apoptosis, and target genes suggested that miR-30a-3p decreases cell proliferation and promotes apoptosis through targeting AKT3. Therefore, $m i R-30 a-3 p$ may be a promising biomarker for the early screening of high-risk populations and early diagnosis of LUAD. Our studies provide insights into identifying novel potential biomarkers for diagnosis and prognosis of LUAD.
\end{abstract}

Correspondence to: Professor Ge-Yu Liang, Key Laboratory of Environmental Medicine Engineering, Ministry of Education, School of Public Health, Southeast University, Nanjing, Jiangsu 210009, P.R. China

E-mail: lianggeyu@163.com

Key words: lung adenocarcinoma, microRNAs, clinical features, miR-30a-3p, AKT3

\section{Introduction}

Lung cancer, the most frequently diagnosed cancer and the leading cause of tumor death, was estimated to account for nearly 1.6 million deaths and more than 1.8 million new cases worldwide in 2012 (1), a sharp rise from 2008 (2). Approximately $80 \%$ of all lung cancer cases are non-small cell lung cancer (NSCLC), and lung adenocarcinoma (LUAD) is a major pathologic subtype of NSCLC, constituting approximately $40 \%$ of diagnosed lung cancers (3). The 5-year survival rate of LUAD has not improved significantly over the past few decades despite great research efforts. Therefore, our focus was improving the early-stage diagnosis of LUAD, specifically identifying and validating biomarkers for early diagnosis and prognosis.

MicroRNAs (miRNAs) are single-stranded non-coding RNA molecules ( 20 nucleotides long) that regulate gene expression at the post-transcriptional level by transcriptional suppression (4-6). miRNAs are frequently dysregulated in various cancers, including LUAD (7), hepatocellular carcinoma (8), gastric (9) and esophageal cancer (10), and may play roles as both oncogenes and antioncogenes $(5,11)$. miRNAs is a major regulatory tool for the epigenome and is also associated with phenotypic consequences of diseases (12). Therefore, identification of LUAD-related miRNAs may contribute to early diagnosis and prognosis.

Studies of LUAD have reported aberrantly expressed miRNAs that regulate initiation, development and metastasis (13-15). However, small studies do not have sufficient power to relate dysregulated miRNAs to clinical features. Recently, Xie et al (16) analyzed 1341 NSCLCs in The Cancer Genome Atlas (TCGA) (http://cancergenome.nih.gov/) and found that genetic variants in regulatory regions of miRNAs might be related to lung cancer risk and survival. However, there are few studies involving both large-scale samples and microarray detection, and the relationships between tumor-specific key miRNAs and clinical features remain uncertain. The TCGA database is a large-scale public data platform from which sequencing data on miRNA and detailed clinical features of LUAD can be downloaded $(17,18)$. To improve the reliability 


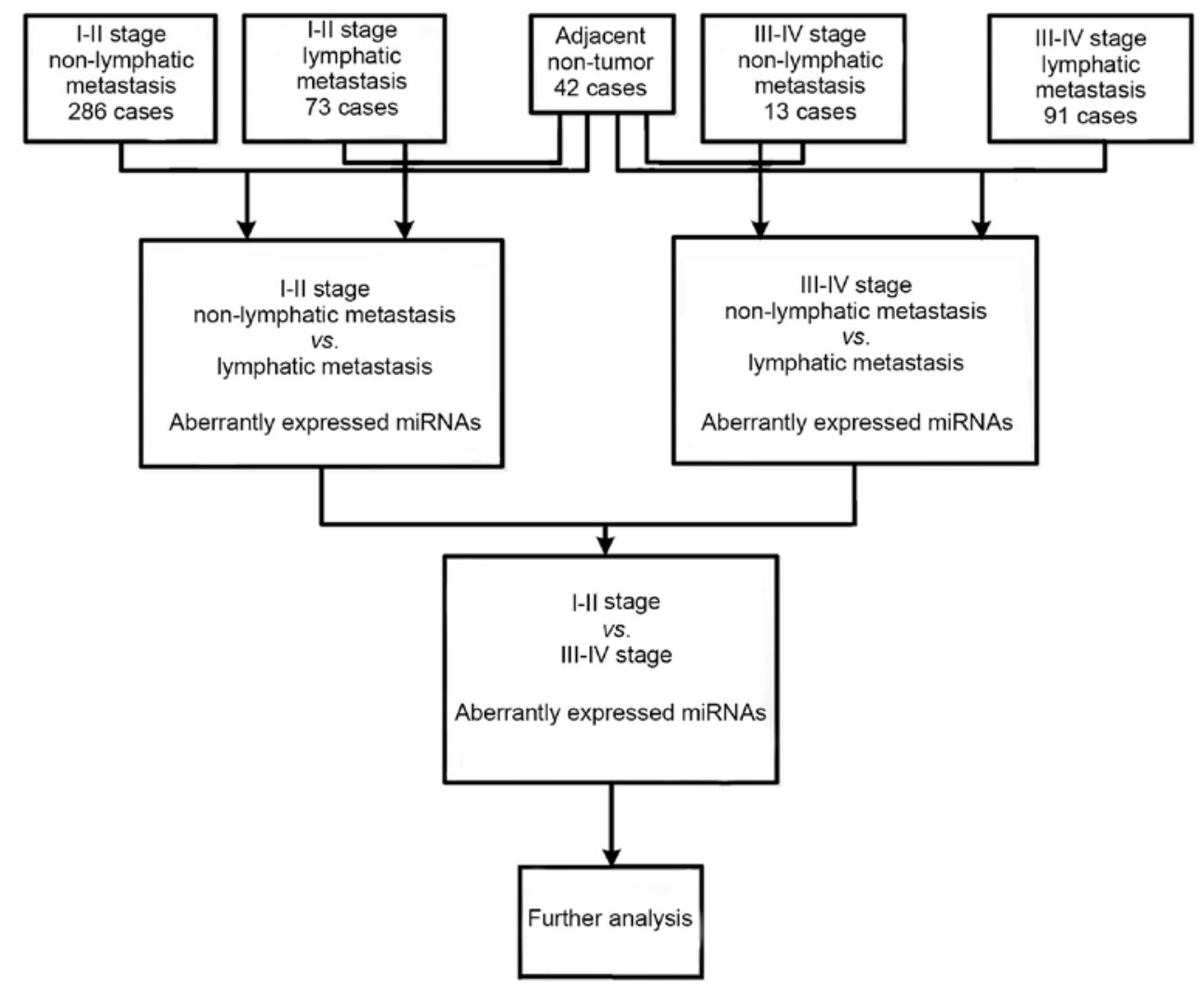

Figure 1. Flow chart for bioinformatics analysis.

and accuracy of the present study, miRNAs in LUAD were identified using the TCGA dataset.

miRNA sequencing data from 463 LUAD samples and 42 adjacent non-tumor lung tissue samples were collected from the TCGA database. This is the first study that has grouped tumor-specific micRNA profiles from the TCGA with pivotal clinical features (TNM stage and lymphatic metastases) in LUAD. Quantitational real-time polymerase chain reaction (qRT-PCR) was used to verify the accuracy of miRNA results in LUAD tumor tissues and adjacent non-tumor lung tissues. The biological function of the LUAD-specific key miRNA $m i R-30 a-3 p$ was further analyzed. The present study was designed to help find potential biomarkers for diagnosis and prognosis based on detailed tumor-specific miRNA expression profiles in LUAD.

\section{Materials and methods}

Patients and samples. The LUAD and adjacent non-tumor tissue miRNA sequencing data and related clinical information for 521 LUAD patients were obtained from the TCGA Data Portal (as of March 2016). Patient exclusion criteria were as follows: i) first histologic diagnosis was not LUAD; ii) presence of another malignancy besides LUAD; iii) incomplete data for analysis; and iv) overall survival more than five years. A total of 463 LUAD patients were included in this study. miRNA expression profiles for normal lung tissue samples were obtained from adjacent non-tumor lung tissues $(n=42)$. According to the staging system of the Union for International Cancer Control (UICC), 359 cases were well and moderately differentiated LUAD (stage I-II) and 104 were poorly differ- entiated LUAD (stage III-IV). In addition, among these 463 LUAD patients were 170 patients with lymphatic metastasis and 295 with non-lymphatic metastasis. The present study meets the publication guidelines of the TCGA.

In addition, 53 LUAD tissue specimens (tumor tissues and paired adjacent non-cancerous tissues) that we collected from Chinese Han population were obtained from the Nanjing Chest Hospital Medical School of Southeast University. Tissues were frozen with RNAlater (Ambion, Foster City, CA, USA) and stored at $-80^{\circ} \mathrm{C}$ immediately after surgical resection until further analysis. Samples were collected with a detailed paper pathology report and a quality assessment report verifying collection of tumor and/or adjacent non-tumor lung tissues. Informed consent forms were obtained from all the patients. The present study was approved by the ethics committee of the Zhongda Hospital Southeast University.

Identification of abnormally expressed intersection miRNAs in LUAD. To identify miRNAs abnormally expressed in LUAD compared with normal lung tissues, the 'Level 3' raw counts of miRNA expression from the TCGA database were analyzed using Illumina HiSeq Systems (Illumina, Inc., Hayward, CA, USA), 463 LUAD samples and 42 normal controls were not further normalized, because these data were already normalized by TCGA. Then, abnormally expressed miRNAs were compared in Level 3, including LUAD tumor tissues vs. adjacent non-tumor lung tissues, lymphatic vs. non-lymph node metastasis in LUAD patients and stage I-II vs. stage III-IV. Finally, intersection miRNAs were selected for further analysis. A flow chart for bioinformatics analysis is presented in Fig. 1. 
The correlations between LUAD-specific intersection miRNAs, clinical features and overall survival. According to the comparative analysis of LUAD miRNA sequencing data in TCGA, LUAD-specific intersection miRNAs were selected. The correlations between LUAD-specific intersection miRNAs and clinical features, including race, sex, age, TNM stage, lymphatic metastasis and patient outcome were further analyzed. Subsequently, to correlate specific intersection miRNAs with patient prognostic characteristics, the univariate Cox proportional hazards regression model was used to analyze the association between specific intersection miRNAs and LUAD patient survival. The Kaplan-Meier and log-rank methods (Mantel-Haenszel test) were used to test the equality of survival distributions in different groups subjected to comparison (19). Hazard ratios (HRs) for a 2-fold change in gene expression level from univariate Cox regression analysis were used to identify LUAD-specific intersection miRNAs associated with overall survival (20). miRNAs defined as having a protective signature showed $\mathrm{HR}<1$ and those defined as high-risk had HR for death $>1$.

Total RNA extraction and $q R T-P C R$ verification. We randomly selected 5 specific key miRNAs in the above bioinformatics analysis and measured their actual expression levels in 53 diagnosed LUAD patients' tumor tissues and adjacent non-tumor tissues by qRT-PCR. U6 was used as an internal normalized reference to confirm reliability and validity. Reverse transcription reactions using the ReverTra Ace ${ }^{\circledR}$ qPCR RT kit (FSQ-101; Toyobo, Shanghai, China) was conducted in two steps according to the manufacturer's protocol. First, the mixture containing $1 \mu \mathrm{g}$ of RNA samples was incubated in a 96-well plate for $5 \mathrm{~min}$ at $65^{\circ} \mathrm{C}$ and held at $4^{\circ} \mathrm{C}$. Then, the $9 \mu \mathrm{l}$ mixture, which comprised $2 \mu \mathrm{l}$ 5X RT buffer, $0.5 \mu \mathrm{l}$ RT Enzyme Mix, $0.5 \mu 1$ miRNA-specific stem-loop RT primers (Guangzhou RiboBio, Co., Ltd., Guangzhou, China), and $6 \mu 1$ $\mathrm{ddH}_{2} \mathrm{O}$, was incubated in a 96 -well plate at $37^{\circ} \mathrm{C}$ for $15 \mathrm{~min}$, $98^{\circ} \mathrm{C}$ for 5 min and subsequently held at $4^{\circ} \mathrm{C}$.

Real-time PCR was performed to detect the expression level of the candidate miRNAs with the StepOne Plus ${ }^{\mathrm{TM}} \mathrm{PCR}$ System (Applied Biosystems, Foster City, CA, USA). QRT-PCR was then performed using Thunderbird ${ }^{\mathrm{TM}} \mathrm{SYBR}^{\circledR}$ qPCR Mix (QPS-201; Toyobo) according to the manufacturer's protocol. The PCR reaction components were $2 \mu \mathrm{l}$ of cDNA, $10 \mu \mathrm{l}$ of Thunderbird SYBR ${ }^{\circledR}$ qPCR Mix, $0.6 \mu 1(1 \mu \mathrm{l} / \mathrm{pmol})$ PCR primers (ribobio), and 13.2 $\mu \mathrm{l}$ RNase-free water. The reaction was performed at $95^{\circ} \mathrm{C}$ for $1 \mathrm{~min}$, followed by 45 cycles of $95^{\circ} \mathrm{C}$ for $15 \mathrm{sec}, 60^{\circ} \mathrm{C}$ for $30 \mathrm{sec}$ and $72^{\circ} \mathrm{C}$ for $30 \mathrm{sec}$. A dissociation curve was analyzed from 60 to $95^{\circ} \mathrm{C}$. The $\mathrm{Ct}$-value for each sample was calculated with the $\Delta \Delta \mathrm{Ct}$ method (21), and fold change results were presented as $2^{-\Delta \Delta \mathrm{Ct}}$, where $\Delta \Delta \mathrm{Ct}=$ $\left(\mathrm{Ct}_{\text {miRNAs }}-\mathrm{Ct}_{\mathrm{U} 6}\right)_{\text {tumor }}-\left(\mathrm{Ct}_{\text {miRNAs }}-\mathrm{Ct}_{\mathrm{U} 6}\right)_{\text {adjacent non-tumor tissues }}$.

Functional enrichment analysis. DIANA-mirPath software (http://diana.cslab.ece.ntua.gr/pathways/) was applied to perform online gene enrichment analysis of putative targets of 25 LUAD-specific key miRNAs, comparing each set of miRNA targets to all known Kyoto Encyclopedia of Genes and Genomes (KEGG) Pathways. Then LUAD-specific key miRNAs and signaling pathways were evaluated using the negative logarithm of P-value (-lg P-value), in which the value was proportional to relevance. Furthermore, interaction and reaction networks between genes were analyzed according to the pathway data available from the KEGG database (http:// www.Genome.jp/kegg/pathway.html).

Cell culture and detection of the expression of miR-30a-3p in lung cell lines. HBE cells and human LUAD cells (A549) were purchased from the Chinese Academy of Sciences Type Culture Collection Cell Library Committee (Shanghai, China). HBE cells and A549 cells were separately cultured in Dulbecco's modified Eagle's medium (DMEM) and 1640 cell-culture medium (HyClone Laboratories, Inc., Logan, UT, USA), supplemented with $10 \%$ fetal bovine serum (FBS; Gibco, Carlsbad, CA, USA), and $100 \mathrm{U} / \mathrm{ml}$ penicillin and $100 \mathrm{mg} / \mathrm{ml}$ streptomycin (HyClone Laboratories), in a humidified 5\% $\mathrm{CO}_{2}$ incubator at $37^{\circ} \mathrm{C}$. The expression status of $m i R-30 a-3 p$ was further confirmed by qRT-PCR before they were used in experiments.

Transfection of miR-30a-3p mimic. Transfections were performed using riboFect ${ }^{\mathrm{TM}} \mathrm{CP}$ Transfection kit (Guangzhou RiboBio) according to the manufacturer's instructions. A549 cells were trypsinized during logarithmic growth period and resuspended in normal growth medium at $1 \times 10^{5} \mathrm{cells} / \mathrm{ml}$. Cells $\left(2 \times 10^{5} /\right.$ well $)$ were seeded in a 6 -well plate with 1640 cellculture medium the day before transfection, then transfected with $5 \mu 1$ miR-30a-3p mimic (50 nM; Guangzhou RiboBio)/ mimic negative control (Guangzhou RiboBio). The transfection complexes were dispensed into wells and incubated at $37^{\circ} \mathrm{C}$ for $24 \mathrm{~h}$. After transfection, qRT-PCR was used to test the expression of $m i R-30 a-3 p$ transfected cells and confirm transfection efficiency.

Cell proliferation detection. The MTT [3-(4, 5-dimethyl)-2, 5-diphenyl-2H] assay was used to assess cell proliferation. Five thousand A549 cells were seeded into each well of a 96-well plate. Cells were transfected in triplicate repeated wells with $50 \mathrm{nM} m i R-30 a-3 p$ mimic and mimic negative control and then cultured in complete culture medium for $24 \mathrm{~h}$. The culture supernatants were removed, and $200 \mu \mathrm{l}$ MTT solution $(0.5 \mathrm{mg} / \mathrm{ml})$ was added into each well and incubated for $4 \mathrm{~h}$ at $37^{\circ} \mathrm{C}$. Then supernatants were removed, and $150 \mu 1$ dimethyl sulphoxide (DMSO) solution was added into each well and vibrated to dissolve formazan crystals. Optical density (OD) value was measured at $570 \mathrm{~nm}$ in a microtiter plate reader.

Flow cytometric analysis. A549 cells $\left(\mathrm{n}=2 \times 10^{5}\right)$ were seeded into each well of a 6-well plate. Cells were transfected in sextuplicate repeated wells with $50 \mathrm{nM} m i R-30 a-3 p$ mimic and mimic negative control, and then were cultured in complete culture medium for $48 \mathrm{~h}$. Cells were harvested by trypsinization in a tube and were washed twice in icecold phosphate-buffered saline (PBS). After staining with fluorescein isothiocyanate (FITC)-Annexin V and propidium iodide (PI) using the FITC Annexin V/PI apoptosis detection kit (Becton-Dickinson, Franklin Lakes, NJ, USA) according to the manufacturer's protocol. The cells were analyzed for apoptosis using a flow cytometer (FACScan; Becton-Dickinson). 
Table I. Abnormal expression of intersection miRNAs in LUAD.

\begin{tabular}{|c|c|c|c|c|c|c|}
\hline miRNA & Accession & Regulation & miRNA_Sequencing & Fold change & $-\log (\mathrm{p})$ & $-\log (\mathrm{FDR})$ \\
\hline$h s a-m i R-30 a-3 p$ & MIMAT0000088 & Down & CUUUCAGUCGGAUGUUUGCAGC & $-5.738 \pm 0.425$ & 7.000 & 6.082 \\
\hline hsa-miR-139-5p & MIMAT0000250 & Down & UCUACAGUGCACGUGUCUCCAGU & $-4.356 \pm 0.219$ & 3.615 & 1.930 \\
\hline$h s a-m i R-133 a-3 p$ & MIMAT0000427 & Down & UUUGGUCCCCUUCAACCAGCUG & $-7.1591 \pm 2.015$ & 4.447 & 2.652 \\
\hline$h s a-m i R-378 a-3 p$ & MIMAT0000732 & Down & ACUGGACUUGGAGUCAGAAGGC & $-4.789 \pm 0.418$ & 5.021 & 3.194 \\
\hline$h s a-m i R-451 a$ & MIMAT0001631 & Down & AAACCGUUACCAUUACUGAGUU & $-6.3753 \pm 1.660$ & 3.609 & 1.926 \\
\hline$h s a-m i R-486-5 p$ & MIMAT0002177 & Down & UCCUGUACUGAGCUGCCCCGAG & $-19.740 \pm 3.61$ & 7.000 & 5.397 \\
\hline$h s a-m i R-30 c-2-3 p$ & MIMAT0004550 & Down & CUGGGAGAAGGCUGUUUACUCU & $-11.1261 \pm 0.805$ & 7.000 & 6.082 \\
\hline hsa-miR-139-3p & MIMAT0004552 & Down & UGGAGACGCGGCCCUGUUGGAGU & $-12.599 \pm 0.974$ & 6.323 & 4.427 \\
\hline$h s a-m i R-221-5 p$ & MIMAT0004568 & Down & ACCUGGCAUACAAUGUAGAUUU & $-4.1656 \pm 0.472$ & 4.840 & 3.022 \\
\hline$h s a-m i R-338-5 p$ & MIMAT0004701 & Down & AACAAUAUCCUGGUGCUGAGUG & $-4.8169 \pm 0.599$ & 6.097 & 4.205 \\
\hline$h s a-m i R-378 c$ & MIMAT0016847 & Down & ACUGGACUUGGAGUCAGAAGAGUGG & $-3.9291 \pm 0.199$ & 5.854 & 3.975 \\
\hline hsa-miR-3614-5p & MIMAT0017992 & Down & CCACUUGGAUCUGAAGGCUGCCC & $-2.897 \pm 0.272$ & 4.932 & 3.109 \\
\hline$h s a-m i R-33 a-5 p$ & MIMAT0000091 & Up & GUGCAUUGUAGUUGCAUUGCA & $4.683 \pm 0.385$ & 6.398 & 4.535 \\
\hline$h s a-m i R-96-5 p$ & MIMAT0000095 & Up & UUUGGCACUAGCACAUUUUUGCU & $5.375 \pm 0.271$ & 7.000 & 5.449 \\
\hline hsa-miR-196a-5p & MIMAT0000226 & Up & UAGGUAGUUUCAUGUUGUUGGG & $9.443 \pm 4.866$ & 3.691 & 2.131 \\
\hline hsa-miR-182-5p & MIMAT0000259 & Up & UUUGGCAAUGGUAGAACUCACACU & $6.415 \pm 0.526$ & 4.862 & 3.131 \\
\hline$h s a-m i R-210-3 p$ & MIMAT0000267 & Up & CUGUGCGUGUGACAGCGGCUGA & $28.035 \pm 5.343$ & 7.000 & 6.149 \\
\hline$h s a-m i R-142-3 p$ & MIMAT0000434 & Up & UGUAGUGUUUCCUACUUUAUGGA & $6.608 \pm 0.888$ & 3.695 & 2.134 \\
\hline$h s a-m i R-9-5 p$ & MIMAT0000441 & Up & UCUUUGGUUAUCUAGCUGUAUGA & $20.480 \pm 3.673$ & 6.347 & 4.482 \\
\hline$h s a-m i R-135 b-5 p$ & MIMAT0000758 & Up & UAUGGCUUUUCAUUCCUAUGUGA & $4.980 \pm 0.548$ & 3.699 & 2.138 \\
\hline$h s a-m i R-143-5 p$ & MIMAT0004599 & Up & GGUGCAGUGCUGCAUCUCUGGU & $3.143 \pm 0.604$ & 7.000 & 5.449 \\
\hline$h s a-m i R-127-5 p$ & MIMAT0004604 & Up & CUGAAGCUCAGAGGGCUCUGAU & $3.283 \pm 0.403$ & 3.918 & 2.321 \\
\hline$h s a-m i R-708-5 p$ & MIMAT0004926 & Up & AAGGAGCUUACAAUCUAGCUGGG & $5.228 \pm 0.396$ & 6.372 & 4.506 \\
\hline$h s a-m i R-708-3 p$ & MIMAT0004927 & Up & CAACUAGACUGUGAGCUUCUAG & $5.993 \pm 0.250$ & 4.842 & 3.113 \\
\hline$h s a-m i R-3607-3 p$ & MIMAT0017985 & Up & ACUGUAAACGCUUUCUGAUG & $9.643 \pm 4.630$ & 5.577 & 3.760 \\
\hline
\end{tabular}

Down, downregulation; up, upregulation.

Apoptosis assessment by Hoechst 33258 staining. A549 cells were placed in 24 -well plates $\left(5 \times 10^{4} /\right.$ well) and transfected with $50 \mathrm{nM}$ miR-30a-3p mimic and mimic negative control, and then cultured in complete culture medium for $48 \mathrm{~h}$. After incubation, cells were washed in PBS and incubated with the DNA dye Hoechst 33258 according to the manufacturer's protocol. The results were visualized under a fluorescent microscope with excitation at a wavelength of $350 \mathrm{~nm}$ and measured at $460 \mathrm{~nm}$. Each test was carried out at least three times.

Western blot assays. After homogenization of the transfected cells, protein concentration was measured using the BCA protein assay (Generay Biotech, Co., Ltd., Shanghai, China). Protein samples were separated using $10 \%$ sodium dodecyl sulfate-polyacrylamide gel electrophoresis and transferred onto nitrocellulose membranes. After membranes were blocked in $10 \%$ BSA for $2 \mathrm{~h}$, immunoblotting was conducted by incubation with the primary antibodies overnight at $4^{\circ} \mathrm{C}$. In the present study, GAPDH (D16H11) $\mathrm{XP}^{\circledR}$ Rabbit mAb (37 kDa) (22) and AKT3 (E1Z3W) Rabbit mAb (60 kDa) (23) antibodies were purchased from Cell Signaling (Danvers, MA, USA). After incubation with HRP-conjugated goat anti-rabbit IgG (D110058; Sangon Biotech Shanghai, Co., Ltd., Shanghai, China) cells were incubated with secondary antibodies for $1 \mathrm{~h}$ at room temperature. Immunoreactive bands were visualized

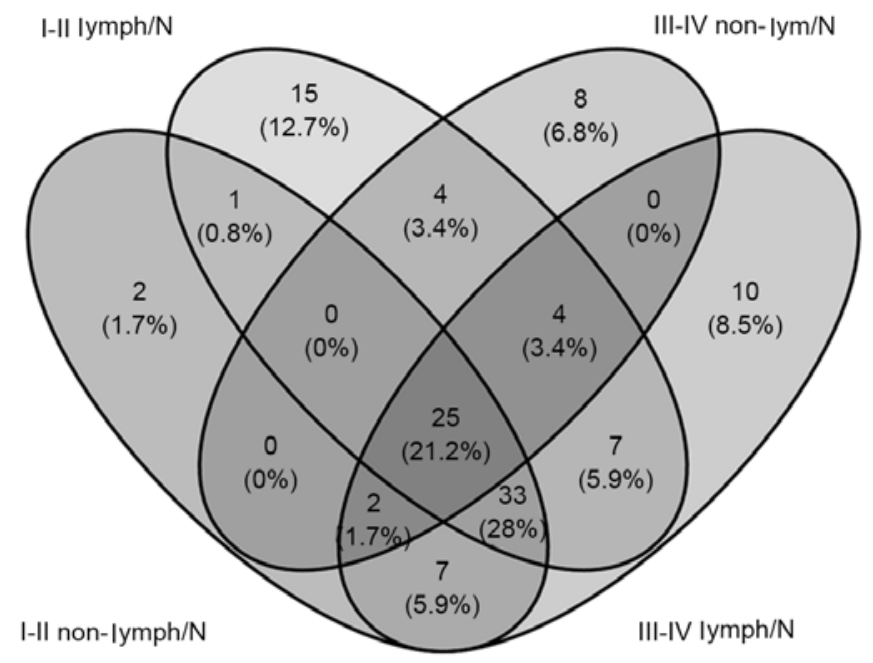

Figure 2. Venn diagram analysis of aberrantly expressed miRNAs between I-II Lymph/N, I-II non-Lym/N, III-IV Lymph/N and III-IV non-Lym/N. Lymph, lymphatic metastasis; non-Lym, non-lymphatic metastasis; $\mathrm{N}$ represents adjacent non-tumor lung tissues.

using a chemiluminescent substrate (Millipore, Darmstadt Germany) and analyzed with an automatic chemical luminescence/fluorescence image analysis system called the Gel 

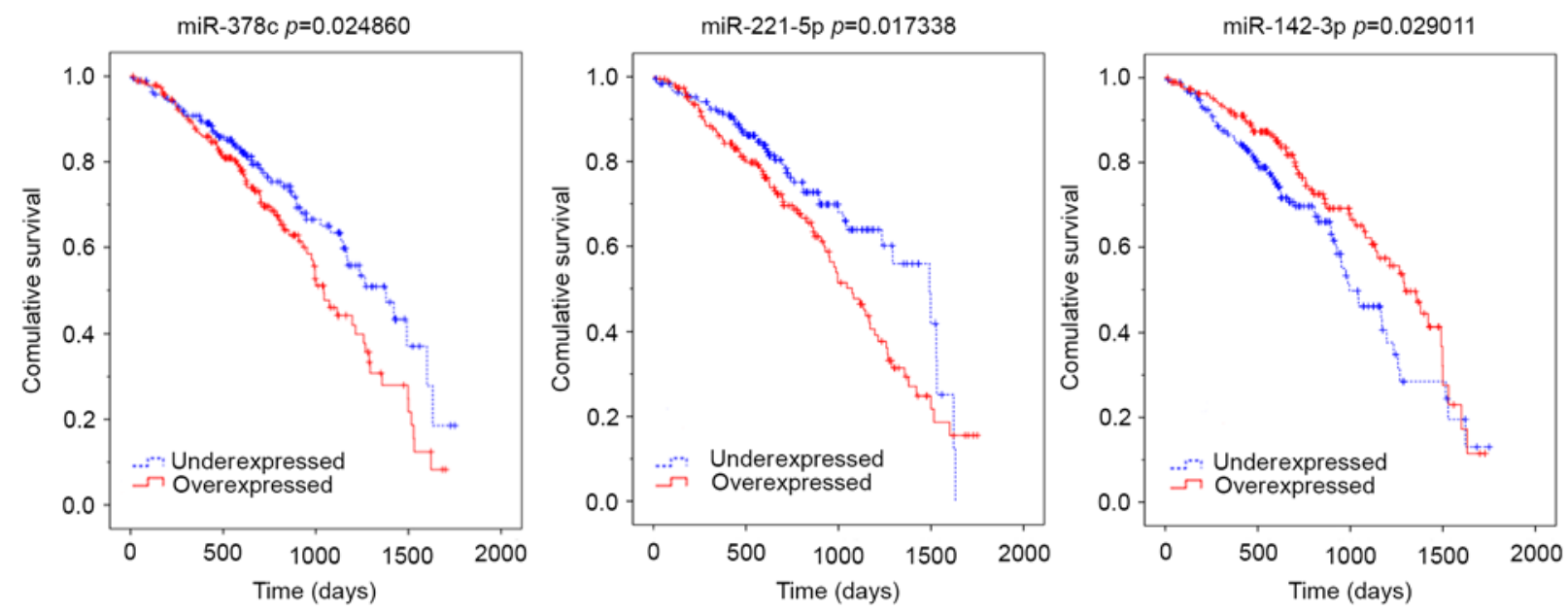

Figure 3. Kaplan-Meier survival curves for three miRNAs associated with overall survival. Horizontal axis, overall survival time, days; vertical axis, survival function.

Table II. The correlations between LUAD-specific intersection miRNAs and clinical features.

\begin{tabular}{|c|c|c|}
\hline Comparisons & Downregulated & Upregulated \\
\hline Race (White vs. Asian) & & $m i R-96-5 p$ \\
\hline Gender (female vs. male) & $\begin{array}{l}m i R-133 a-3 p, m i R-139 a-3 p \\
m i R-30 a-3 p, m i R-30 c-2-3 p\end{array}$ & $m i R-127-5 p, m i R-196 a-5 p$ \\
\hline Age ( $\leq 60$ vs. $>60$ years $)$ & $m i R-338-5 p, m i R-378 c$ & \\
\hline TNM stage (I-II vs. III-IV) & $m i R-221-5 p, m i R-378 a-3 p, m i R-451 a, m i R-486-5 p$ & \\
\hline Lymphatic metastasis (no vs. yes) & $m i R-133 a-3 p, m i R-139-5 p, m i R-221-5 p$ & \\
\hline Patient outcome assessment (dead vs. alive) & $\begin{array}{l}m i R-133 a-3 p, m i R-139-5 p, m i R-221-5 p \\
m i R-30 a-3 p, m i R-30 c-2-3 p, m i R-378 c\end{array}$ & $m i R-33 a-5 p$ \\
\hline
\end{tabular}

Imaging System (Tanon Science \& Technology, Co., Ltd, Shanghai, China).

Statistical analysis. The data are shown as mean \pm SD and statistical comparisons were made using the Student's t-test. The significance level was set as 0.05 as default to control the false discovery rate (FDR). Values of $\mathrm{P}<0.05$ were considered statistically significant. Statistical analyses were performed using SPSS 19.0. Operating characteristic curve (ROC) was used to determine the specific key miRNAs as the sensitivity and specificity of detection of LUAD.

\section{Result}

Identification of abnormally expressed miRNAs in LUAD patients. In the present study, a total of 1030 miRNAs were identified from TCGA 'Level 3' LUAD RNA-Sequencing data. Then 118 LUAD-associated abnormally expressed miRNAs were identified between 463 LUAD tumor tissue samples and 42 adjacent non-tumor tissues. Furthermore, we compared these 118 miRNAs between tumor stage and lymphatic metastasis. Seventy aberrantly expressed miRNAs were selected from comparisons of stage I-II (non-lymphatic metastasis) LUAD patient tissues and adjacent non-tumor lung tissues, 43 from comparisons of stage I-II (lymphatic metastasis) with adjacent non-tumor lung tissues, 89 from comparisons of stage III-IV (non-lymphatic metastasis) and adjacent non-tumor tissues and 88 from comparisons of stage III-IV (lymphatic metastasis) and adjacent non-tumor tissues. To further confirm data reliability, we selected 25 aberrantly expressed miRNAs (12 downregulated and 13 upregulated) from the intersection of the above four groups (Fig. 2 and Table I).

The correlations between LUAD-specific miRNAs and clinical features. The 25 LUAD-specific intersection miRNAs were further analyzed according to their expression and clinical features (race, sex, age, TNM stage, lymphatic metastasis and patient outcome assessment at diagnosis in the TCGA database). Fifteen specific miRNAs were significantly aberrantly expressed in clinical feature comparisons $(\mathrm{P}<0.05$; Table II).

One miRNA (miR-96-5p) was aberrantly expressed in race, 6 miRNAs (miR-133a-3p, miR-139a-3p, miR-30a-3p, $m i R-30 c-2-3 p, m i R-127-5 p$ and $m i R-196-5 p)$ were aberrantly expressed in sex, 2 miRNAs ( $m i R-338-5 p$ and $m i R-378 c$ ) were aberrantly expressed in age, 4 miRNAs ( $m i R-221-5 p$, $m i R-378 a-3 p, m i R-451 a$ and $m i R-486-5 p)$ were aberrantly expressed in TNM stage, 3 miRNAs ( $m i R-133 a-3 p, m i R-139-5 p$ and $m i R-221-5 p$ ) were aberrantly expressed in lymphatic metastasis and 6 miRNAs (miR-133a-3p, miR-139-5p, 


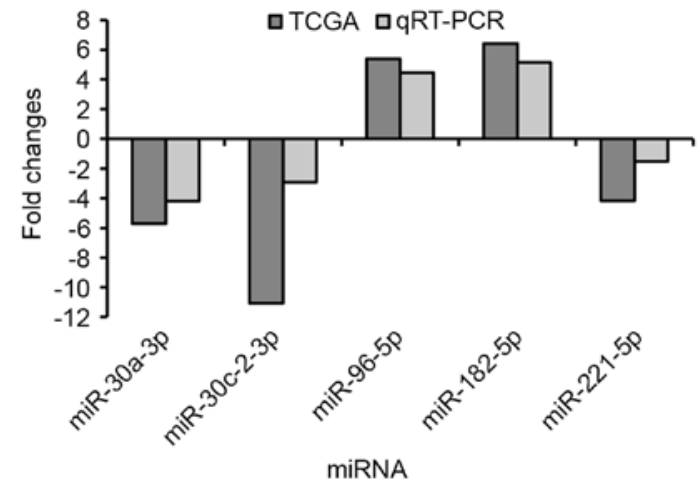

Figure 4. QRT-PCR validation of 5 aberrantly expressed key miRNAs. Comparison of fold change $\left(2^{-\Delta \Delta C t}\right)$ of miRNAs between TCGA and qRT-PCR results.

$m i R-221-5 p, m i R-30 a-3 p, m i R-378 c$ and $m i R-33 a-5 p)$ were aberrantly expressed in patient outcome.

Survival analysis. A univariate Cox model was used to investigate the relationship between the the 25 LUAD-specific intersection miRNAs and overall survival. Three of these miRNAs were significantly associated with overall survival status in 463 LUAD patients (log-rank $\mathrm{P}<0.05)$ : 2 (miR-378c and $m i R-221-5 p)$ negatively $(\mathrm{P}<0.05)$ and $1(m i R-142-3 p)$ positively $(\mathrm{P}<0.05)$ (Fig. 3).

$q R T-P C R$ verification. Finally, we randomly selected 5 specific key miRNAs (miR-30a-3p, miR-30c-2-3p, miR-96-5p, $m i R-182-5 p$ and $m i R-221-5 p$ ) to validate the reliability and validity of the results of the above miRNA analysis. We applied the paired t-test to assess the differences between the 53 newly diagnosed LUAD tumor tissues and the adjacent non-tumor lung tissues. The results showed that $m i R-30 a-3 p$, $m i R-30 c-2-3 p$ and $m i R-221-5 p$ were downregulated in LUAD tumor tissues compared with adjacent non-tumor lung tissues, while $m i R-96-5 p$ and $m i R-182-5 p$ were upregulated in LUAD tumor tissues (Fig. 4). The results from the qRT-PCR validation in 53 newly diagnosed LUAD patients were consistent with the above bioinformatics results (Table I).

ROC curve analysis of specific key miRNAs. ROC curve analysis demonstrated that the area under curve (AUC) $=0.837$, 0.819 and 0.835 for $m i R-30 a-3 p, m i R-96-5 p$ and $m i R-182-5 p$ $(\mathrm{P}<0.01$; Fig. 5A, C and $\mathrm{D})$, which are the score both higher the cut-off (0.7) and could be considerable biomarker for early diagnosis of LUAD. ROC analysis measured an AUC $=0.674$ and 0.546 for $m i R-30 c-2-3 p$ and $m i R-221-5 p(\mathrm{P}<0.01$; Fig. 5B and $\mathrm{E})$, which both are scores very close to the cut-off (0.7) needed for a considerable biomarker for early diagnosis of LUAD.

Functional enrichment analysis. To further confirm a possible link between miRNA and cell function, DIANA-mirPath software was used to perform differential expression analysis of miRNAs involved in signaling pathways. The bio-informatics analysis indicated that $m i R-30 a-3 p$ plays an important role in NSCLC (Fig. 6). It was also indicated that several genes were regulated by $m i R-30 a-3 p$ to activate the process of apoptosis
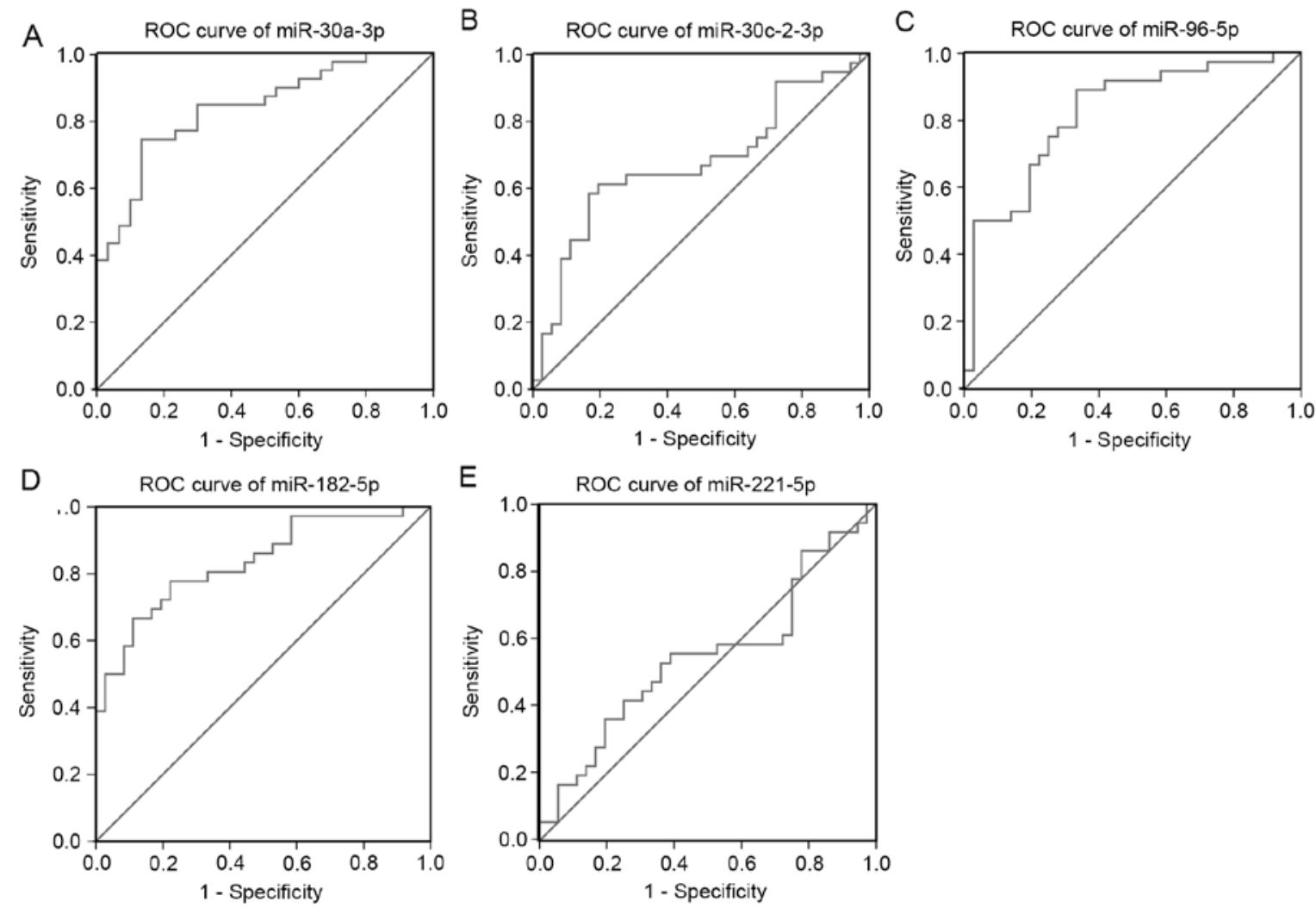

Figure 5. ROC curve analysis of specific key miRNAs. 

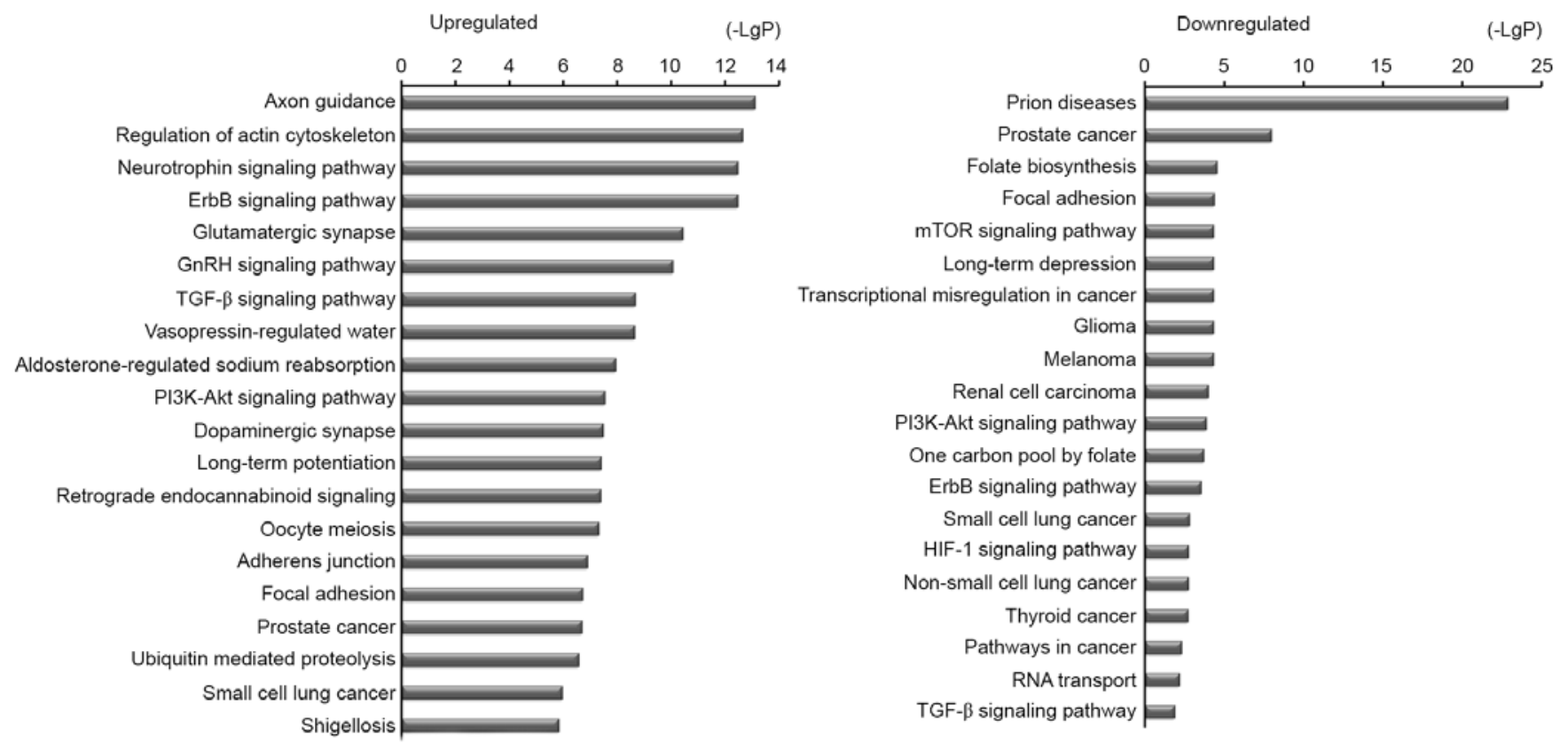

Figure 6. Top 20 enriched KEGG pathways for aberrantly expressed miRNAs (the bar plot shows the enrichment scores for the 20 most significantly enriched KEGG pathways).

Table III. The influence of the expression of miR-30a-3p after $m i R-30 a-3 p$ mimic transfection.

\begin{tabular}{lccc}
\hline & $\begin{array}{c}\Delta \mathrm{CT} \\
(\text { mean } \pm \mathrm{SD})\end{array}$ & $\begin{array}{c}\Delta \Delta \mathrm{CT}) \\
(\text { mean } \pm \mathrm{SD}\end{array}$ & $2^{-\Delta \Delta \mathrm{CT}}$ \\
\hline $\begin{array}{l}\text { miR-30a-3p } \\
\text { mimic group }\end{array}$ & $-0.859 \pm 0.233$ & $-10.855 \pm 0.228$ & 1852.040 \\
$\begin{array}{l}\text { Negative control } \\
\text { 9. }\end{array}$ & $9.548 \pm 1.106$ & & \\
\hline
\end{tabular}

in NSCLC (Fig. 7); for example, AKT3 played an important activating role.

qRT-PCR verification of miR-30a-3p expression in lung cell lines. miR-30a-3p was detected in analysis of miRNAs. QRT-PCR was used to detect the expression of $m i R-30 a-3 p$ expression in HBE cells and A549 cells. The results showed that the qRT-PCR findings were consistent with the TCGA findings (Fig. 8).

Influence of miR-30a-3p mimic on morphology and proliferation of A549 cells. miR-30a-3p mimic was transfected into A549 cells to upregulate the expression of miR-30a-3p. qPCR was performed to determine the efficiency of transfection with the miR-30a-3p mimic. After transfection of the miR-30a-3p mimic, the expression of $m i R-30 a-3 p$ increased significantly (1852.04-fold), compared with negative control (Table III). Light microscopy revealed no significant difference in morphology of miR-30a-3p transfected A549 cells, nor was there any difference in cell density compared with the negative control group. Furthermore, the MTT assay was used to assess the effect of upregulated miR-30a-3p on the viability of A549 cells. The MTT assay showed that after upregulation of $m i R-30 a-3 p$, the proliferation of A549 cells was significantly inhibited ( $\mathrm{P}=0.000$; Fig. 9A).

Examination of miR-30a-3p-induced apoptosis. PI and Annexin V were used to dye A549 cells, and the apoptosis rate was assessed by flow cytometry. The total apoptosis rate of cells in the miR-30a-3p mimic group (17.100\%) was significantly higher than among cells in the negative control $(9.400 \%)$ ( $\mathrm{P}=0.022$; Fig. 9B). Furthermore, nuclear staining with Hoechst 33258 and electron microscopic examination demonstrated that in comparison with negative control cells, typical apoptotic morphological changes (such as cell shrinkage, condensation of cytoplasm and chromatin compaction), were more frequent in miR-30a-3p mimic group cells (Fig. 9C).

Western blot assays. Western blot was applied to measure the effect of expression of the AKT3 gene on protein levels. The expression of the AKT3 gene significantly decreased $(\mathrm{P}=0.002$; Fig. 10) protein levels in the miR-30a-3p mimic group compared with the negative control. This implies that $m i R-30 a-3 p$ might promote A549 cell apoptosis through negative regulation of the $A K T 3$ gene.

\section{Discussion}

LUAD is the most frequent subtype of lung cancer, with high global incidence and mortality (24). Because of immense heterogeneity in multiple parameters (molecular, pathology, surgery and radiology) among LUAD patients, the development of individualized therapy and accurate prognosis have remained a huge challenge (25). Although major improvements in diagnosis, medical treatment and surgical technology of LUAD have been made over the past few decades, the 5-year disease-free survival rate remains $<10 \%$ (26). In the past decade, targeted therapy has been improved, and many target 


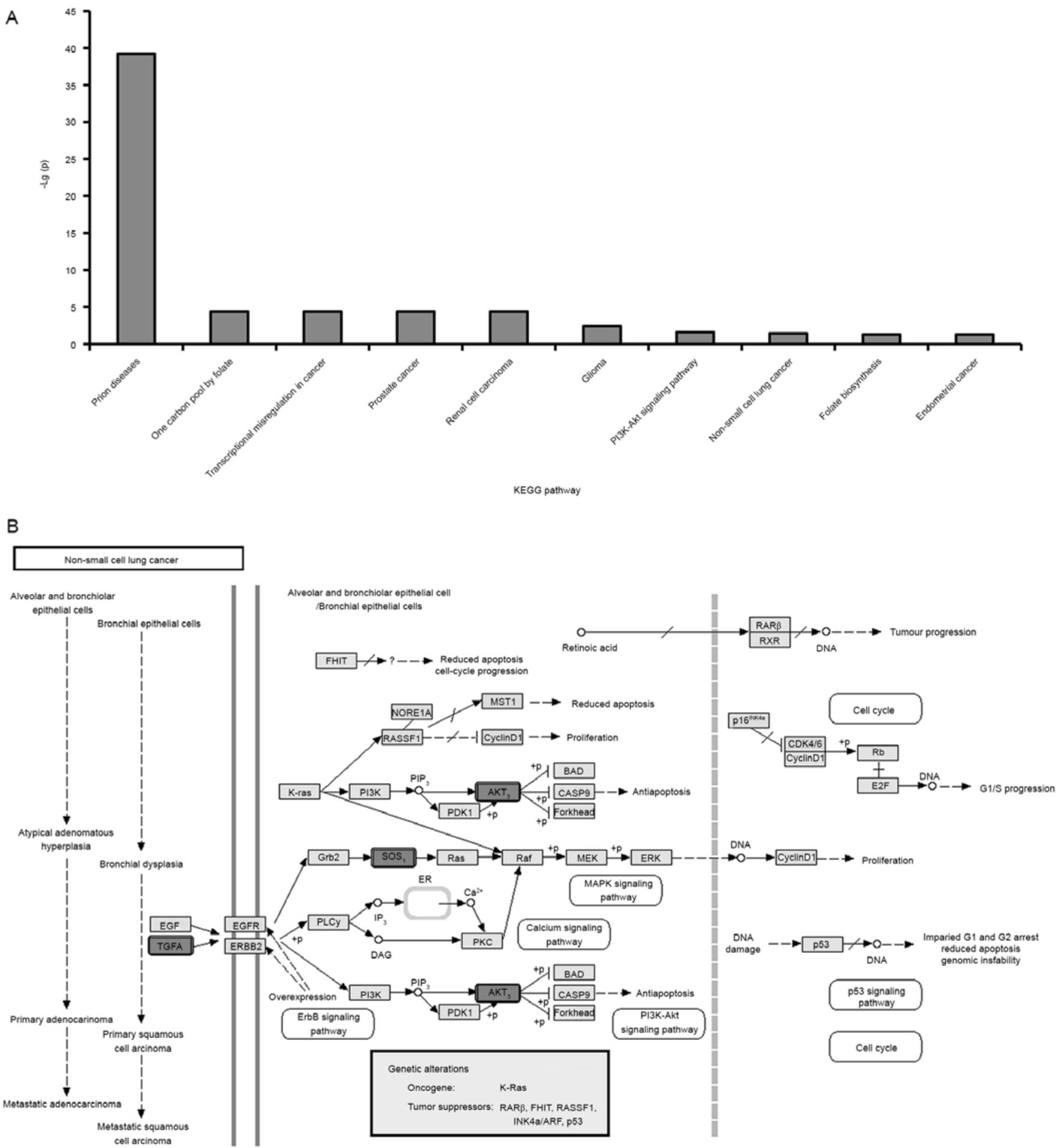

Figure 7. Pathway analysis and target prediction for $m i R-30 a-3 p$. (A) $m i R-30 a-3 p$ involved in signaling pathways; (B) non-small cell lung cancer pathway. The names of genes highlighted are the putative targets of $m i R-30 a-3 p$.

genes, including PIK3CA, PTEN and KRAS, have been identified as having a potentially powerful clinical impact $(27,28)$. However, because of the large numbers of genes and the low prevalence of mutations, miRNAs may be more effective than gene expression profiles in classifying various human cancers (29). miRNAs are small, conserved, non-coding regulatory RNAs that play important roles in initiation and development of carcinoma, and they can interact with the miRNA binding sites on the $3^{\prime}$ untranslated region (3'UTR) and coding sequence of the target gene to regulate normal gene expression (30). Moreover, there is increasing evidence that miRNAs are closely related to initiation and development of LUAD $(31,32)$. Therefore, identification of tumor-related miRNAs and the regulatory mechanisms involved in LUAD has received increasing attention.

In the present study, we identified aberrantly expressed miRNAs in LUAD from the TCGA database. Based on miRNA sequencing profiles in TCGA, we investi- 


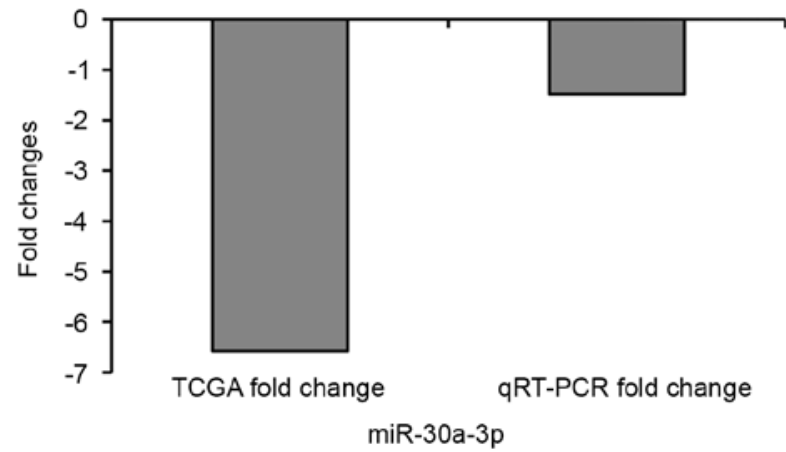

Figure 8. QRT-PCR validation of HBE cells and A549 cells. Comparison of fold change ( $2^{-\Delta \Delta C t}$ ) of $m i R-30 a-3 p$ between TCGA and qRT-PCR results. Fold change $\left(2^{-\Delta \Delta C t}\right)$ of $m i R-30 a-3 p$ of qRT-PCR results: $\Delta \Delta \mathrm{Ct}=\left(\mathrm{Ct}_{m i R-30 a-3 p}\right.$ $\mathrm{CtU6})_{\mathrm{A} 549 \text { cells }}-\left(\mathrm{Ct}_{\text {miR-30a-3p}}-\mathrm{C} t U 6\right)_{\mathrm{HBE} \text { cells }}$.

gated the distribution of LUAD miRNAs in reference to different clinical features and overall survival. We further randomly selected five specific key miRNAs (miR-30a-3p, $m i R-30 c-2-3 p, m i R-96-5 p, m i R-182-5 p$ and $m i R-221-5 p)$ from among 25 specific key miRNAs and measured their expression in 53 LUAD tissue specimens with qRT-PCR. Then, DIANA-miRPath software was used to analyze these 25 specific key miRNAs. miR-30a-3p, known to be involved in the NSCLC pathway and relevant in prognosis of LUAD, was selected for cell functional studies and target gene validation.

Among the 25 specific key miRNAs identified in our bioinformatics analysis, several have been reported to be dysregulated in cancers, including miR-30a-3p (33) $m i R-139-5 p$ (34), miR-133a-3p (35) and miR-221-5p (36). $m i R-486-5 p$ was previously reported to be downregulated in NSCLC tissues and cell lines, and was shown to target CDK4 to regulate cell proliferation, apoptosis and cell cycle progression. Moreover, the upstream promoter of $m i R-486-5 p$ was shown to be strongly regulated by methylation in NSCLC (37). Xiao et al (38) investigated miR-142-3p in NSCLC, and their results suggested that $m i R-142-3 p$ may be a tumor suppressor through downregulating $H M G B 1$ in NSCLC. In addition, $m i R-378 a-3 p, m i R-451 a, m i R-30 c-2-3 p$, $m i R-210-3 p$ and $m i R-708-5 p$ were also reported to be dysregulated in lung cancer and might be related to initiation and development of lung cancer. Eighteen of these 25 specific key miRNAs were not reported in lung cancer.

With respect to the associations between the 25 LUADspecific key miRNAs and clinical features, including race, sex, age, TNM stage, lymphatic metastasis and patient outcome, we found 15 of these 25 LUAD-specific key miRNAs to be related to clinical features, including miR-133a-3p, $m i R-139 a-3 p, m i R-30 a-3 p$ and $m i R-30 c-2-3 p$. All 15 were reported to be associated with human cancer. For example, Chen et al (39) found miR-451a to be downregulated in LUAD and was associated with more advanced pathological stage, larger tumor diameter, and lymphatic metastasis. Only two miRNAs (miR-451a and miR-142-3p) were associated with LUAD clinical features. When associations between 25 LUAD-specific key miRNAs and patient survival were analyzed, three miRNAs were found to be related to LUAD overall survival.

Five of the 25 LUAD-specific key miRNAs (miR-30a-3p, $m i R-30 c-2-3 p, m i R-96-5 p, m i R-182-5 p$ and $m i R-221-5 p$ ) were randomly selected to verify expression of LUADspecific key miRNAs and the accuracy of bioinformatics
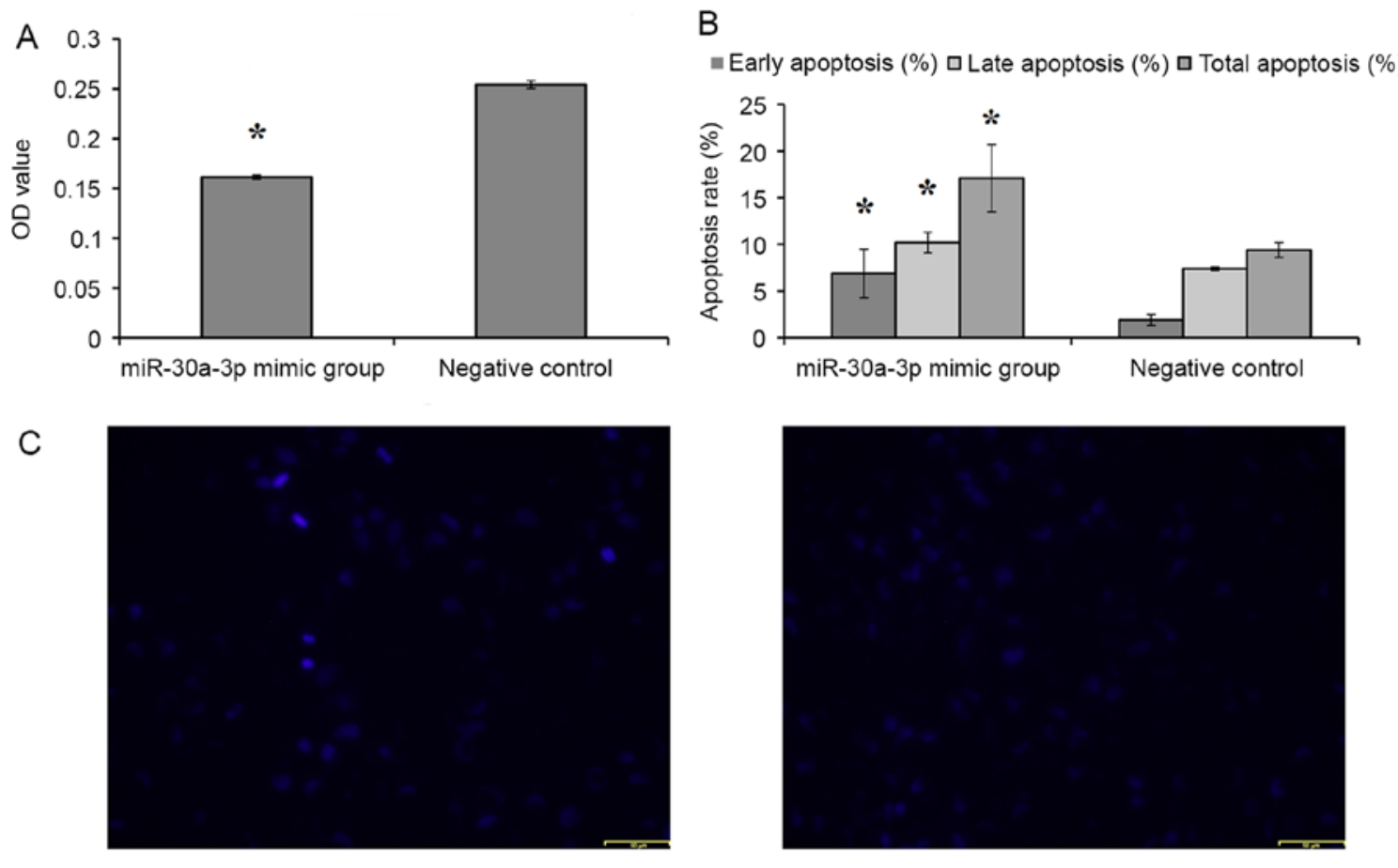

miR-30a-3p mimic group

Negative control

Figure 9. The influence of $m i R-30 a-3 p$ on cell biology function after $m i R-30 a-3 p$ mimic transfection (A) cell proliferation on miR-30a-3p mimic transfected A549 cells; (B and C) cell apoptosis on miR-30a-3p mimic transfected A549 cells (B) Annexin V and PI staining; (C) Hoechst 33258 staining. 

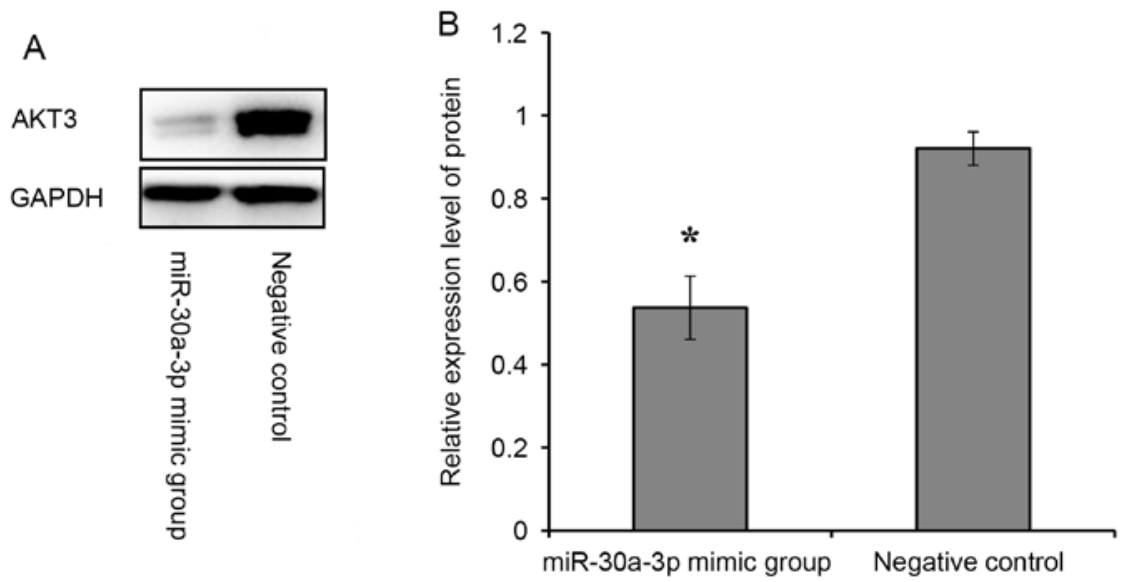

Figure 10 (A,B). Protein expression of AKT3 in A549 cells treated with miR-30a-3p mimic/NC normalized against GAPDH. The AKT3 protein expression was significantly decreased by $m i R-30 a-3 p$ overexpression $(\mathrm{P}<0.05)$.

analysis using qRT-PCR. The expression data from TCGA and verification results from 53 diagnosed LUAD patients were in $100 \%$ agreement, suggesting the credibility of our bioinformatics analysis.

Based on the correlations between LUAD-specific key miRNAs, clinical features from the TCGA, and functional enrichment analysis, $m i R-30 a-3 p$ was found to be strongly related to patient prognosis. Furthermore, it was shown that miR-30a-3p might directly target AKT3 to regulate cell apoptosis. It has been reported that inhibiting $m i R-30 a-3 p$ expression can increase $H I F 2 \alpha$ levels in human clear cell renal cell carcinoma cells and promote cell proliferation, angiogenesis and tumor growth (40). Ma et al (33) detected the expression of $m i R-30 a-3 p$ in colorectal cancer using qRT-PCR compared with adjacent non-tumor tissues and demonstrated that it was descreased. Rodríguez et al (41) found that higher expression of $m i R-30 a-3 p$ was one benefit of treatment for breast cancer. In combination, the above findings suggest that $m i R-30 a-3 p$ might play an important role in tumor progression and prognosis formation in multiple cancers. Finally, we analyzed the cell function of miR-30a-3p in A549 cells and found that miR-30a-3p might regulate cell apoptosis through targeting $A K T 3$. It was also found that transfection with $A K T 3$ siRNA in T98G cells could induce apoptosis (42).

In summary, we identified LUAD-specific key miRNAs from hundreds of candidate miRNAs identified from largescale samples in the TCGA database, and identified aberrant expression profiles of cancer-specific key miRNAs under different clinical features. Moreover, we also analyzed the association among aberrently expressed miRNAs, clinical features and overall survival. QRT-PCR verification was further used to confirm the reliability and validity of expression of LUAD-specific key miRNAs and bioinformatics analysis. ROC was used to determine the specific key miRNAs as the sensitivity and specificity of detection of LUAD. $m i R$ $30 a-3 p$ was selected to assess cell function, and the results confirmed the credibility of functional enrichment analysis. The aberrantly expressed key miRNAs identified in LUAD may provide clues as to sensitive biomarkers in LUAD. Our studies provide novel insight into finding potential biomarkers for diagnosis and prognosis of LUAD.

\section{Acknowledgements}

The present study was supported by the National Natural Science Foundation of China (nos. 81472939, 81502783 and 81673132), the Qing Lan Project, the 333 Project of Jiangsu Province, the Liu Da Ren Cai Gao Feng Project of Jiangsu Province, and the Fundamental Research Funds for the central universities and Innovative Research Project for postgraduates in Colleges of Jiangsu province.

\section{References}

1. Torre LA, Bray F, Siegel RL, Ferlay J, Lortet-Tieulent J and Jemal A: Global cancer statistics, 2012. CA Cancer J Clin 65: 87-108, 2015.

2. Jemal A, Bray F, Center MM, Ferlay J, Ward E and Forman D: Global cancer statistics. CA Cancer J Clin 61: 69-90, 2011.

3. Meng W, Ye Z, Cui R, Perry J, Dedousi-Huebner V, Huebner A, Wang Y, Li B, Volinia S, Nakanishi H, et al: MicroRNA-31 predicts the presence of lymph node metastases and survival in patients with lung adenocarcinoma. Clin Cancer Res 19: 5423-5433, 2013.

4. Lagos-Quintana M, Rauhut R, Lendeckel W and Tuschl T: Identification of novel genes coding for small expressed RNAs. Science 294: 853-858, 2001.

5. Carthew RW and Sontheimer EJ: Origins and mechanisms of miRNAs and siRNAs. Cell 136: 642-655, 2009.

6. Li CY, Liang GY, Yao WZ, Sui J, Shen X, Zhang YQ, Peng H, Hong WW, Ye YC, Zhang ZY, et al: Identification and functional characterization of microRNAs reveal a potential role in gastric cancer progression. Clin Transl Oncol 19: 162-172, 2016.

7. Babu KR and Muckenthaler MU: miR-20a regulates expression of the iron exporter ferroportin in lung cancer. J Mol Med (Berl) 94: 347-359, 2016.

8. Wu W, Dang S, Feng Q, Liang J, Wang Y and Fan N: MicroRNA542-3p inhibits the growth of hepatocellular carcinoma cells by targeting FZD7/Wnt signaling pathway. Biochem Biophys Res Commun 482: 100-105, 2016.

9. Ren C, Chen H, Han C, Fu D, Wang D and Shen M: High expression of miR-16 and miR-451 predicating better prognosis in patients with gastric cancer. J Cancer Res Clin Oncol 142: 2489-2496, 2016.

10. Wang X, Li M, Wang Z, Han S, Tang X, Ge Y, Zhou L, Zhou C, Yuan $\mathrm{Q}$ and Yang M: Silencing of long noncoding RNA MALAT1 by miR-101 and miR-217 inhibits proliferation, migration, and invasion of esophageal squamous cell carcinoma cells. J Biol Chem 290: 3925-3935, 2015.

11. Kent OA and Mendell JT: A small piece in the cancer puzzle: microRNAs as tumor suppressors and oncogenes. Oncogene 25: 6188-6196, 2006. 
12. Borel $\mathrm{C}$ and Antonarakis SE: Functional genetic variation of human miRNAs and phenotypic consequences. Mamm Genome 19: 503-509, 2008.

13. Takamizawa J, Konishi H, Yanagisawa K, Tomida S, Osada H, Endoh H, Harano T, Yatabe Y, Nagino M, Nimura Y, et al: Reduced expression of the let-7 microRNAs in human lung cancers in association with shortened postoperative survival. Cancer Res 64: 3753-3756, 2004.

14. Becker-Santos DD, Thu KL, English JC, Pikor LA, Martinez VD, Zhang M, Vucic EA, Luk MT, Carraro A, Korbelik J, et al: Developmental transcription factor NFIB is a putative target of oncofetal miRNAs and is associated with tumour aggressiveness in lung adenocarcinoma. J Pathol 240: 161-172, 2016.

15. Mou X and Liu S: MiR-485 inhibits metastasis and EMT of lung adenocarcinoma by targeting Flot2. Biochem Biophys Res Commun 477: 521-526, 2016.

16. Xie K, Wang C, Qin N, Yang J, Zhu M, Dai J, Jin G, Shen H, Ma H and $\mathrm{Hu} \mathrm{Z}$ : Genetic variants in regulatory regions of microRNAs are associated with lung cancer risk. Oncotarget 7: 47966-47974, 2016.

17. Sui J, Li YH, Zhang YQ, Li CY, Shen X, Yao WZ, Peng H, Hong WW, Yin LH, Pu YP, et al: Integrated analysis of long non-coding RNA-associated ceRNA network reveals potential lncRNA biomarkers in human lung adenocarcinoma. Int J Oncol 49: 2023-2036, 2016.

18. Li CY, Liang GY, Yao WZ, Sui J, Shen X, Zhang YQ, Peng H, Hong WW, Ye YC, Zhang ZY, et al: Integrated analysis of long non-coding RNA competing interactions reveals the potential role in progression of human gastric cancer. Int $\mathbf{J}$ Oncol 48 : 1965-1976, 2016

19. Xie J and Liu C: Adjusted Kaplan-Meier estimator and log-rank test with inverse probability of treatment weighting for survival data. Stat Med 24: 3089-3110, 2005.

20. Branders S and Dupont P: A balanced hazard ratio for risk group evaluation from survival data. Stat Med 34: 2528-2543, 2015

21. Sana J, Faltejskova P, Svoboda M and Slaby O: Novel classes of non-coding RNAs and cancer. J Transl Med 10: 103, 2012.

22. Wang DY, Wu YN, Huang JQ, Wang W, Xu M, Jia JP, Han G, Mao BB and Bi WZ: Hippo/YAP signaling pathway is involved in osteosarcoma chemoresistance. Chin J Cancer 35: 47, 2016.

23. Mo X, Cao Q, Liang H, Liu J, Li H and Liu F: MicroRNA-610 suppresses the proliferation of human glioblastoma cells by repressing CCND2 and AKT3. Mol Med Rep 13: 1961-1966, 2016.

24. Kerr KM: Pulmonary adenocarcinomas: Classification and reporting. Histopathology 54: 12-27, 2009.

25. Yoshizawa A, Motoi N, Riely GJ, Sima CS, Gerald WL, Kris MG, Park BJ, Rusch VW, Travis WD, et al: Impact of proposed IASLC/ATS/ERS classification of lung adenocarcinoma: prognostic subgroups and implications for further revision of staging based on analysis of 514 stage I cases. Mod Pathol 24: 653-664, 2011.

26. Ortea I, Rodríguez-Ariza A, Chicano-Gálvez E, Arenas Vacas MS and Jurado Gámez B: Discovery of potential protein biomarkers of lung adenocarcinoma in bronchoalveolar lavage fluid by SWATH MS data-independent acquisition and targeted data extraction. J Proteomics 138: 106-114, 2016.

27. De Luca A, Maiello MR, D'Alessio A, Pergameno $M$ and Normanno N: The RAS/RAF/MEK/ERK and the PI3K/AKT signalling pathways: Role in cancer pathogenesis and implications for therapeutic approaches. Expert Opin Ther Targets 16 (Suppl 2): S17-S27, 2012.

28. Cardarella S and Johnson BE: The impact of genomic changes on treatment of lung cancer. Am J Respir Crit Care Med 188: $770-775,2013$
29. Lu J, Getz G, Miska EA, Alvarez-Saavedra E, Lamb J, Peck D, Sweet-Cordero A, Ebert BL, Mak RH, Ferrando AA, et al: MicroRNA expression profiles classify human cancers. Nature 435: 834-838, 2005

30. Cai Y, Yu X, Hu S and Yu J: A brief review on the mechanisms of miRNA regulation. Genomics Proteomics Bioinformatics 7: 147-154, 2009 .

31. Shi X, Xu Y, Zhang C, Feng L, Sun Z, Han J, Su F, Zhang Y, Li C and Li X: Subpathway-LNCE: Identify dysfunctional subpathways competitively regulated by lncRNAs through integrating lncRNA-mRNA expression profile and pathway topologies. Oncotarget 7: 69857-69870, 2016.

32. Wu C, Xu B, Zhou Y, Ji M,Zhang D, Jiang J and Wu C: Correlation between serum IL-1 $\beta$ and miR-144-3p as well as their prognostic values in LUAD and LUSC patients. Oncotarget 7: 85876-85887, 2016.

33. Ma Y, Zhang P, Yang J, Liu Z, Yang Z and Qin H: Candidate microRNA biomarkers in human colorectal cancer: Systematic review profiling studies and experimental validation. Int J Cancer 130: 2077-2087, 2012.

34. Pantaleo MA, Ravegnini G, Astolfi A, Simeon V, Nannini M, Saponara M, Urbini M, Gatto L, Indio V, Sammarini G, et al: Integrating miRNA and gene expression profiling analysis revealed regulatory networks in gastrointestinal stromal tumors. Epigenomics 8: 1347-1366, 2016.

35. Wei Y, He R, Wu Y, Gan B, Wu P, Qiu X, Lan A, Chen G, Wang Q, Lin X, et al: Comprehensive investigation of aberrant microRNA profiling in bladder cancer tissues. Tumour Biol 37: 12555-12569, 2016.

36. Pichler M, Stiegelbauer V, Vychytilova-Faltejskova P, Ivan C, Ling H, Winter E, Zhang X, Goblirsch M, Wulf-Goldenberg A, Ohtsuka M, et al: Genome-wide microRNA analysis identifies miR-188-3p as novel prognostic marker and molecular factor involved in colorectal carcinogenesis. Clin Cancer Res 23: 1323-1333, 2016.

37. Shao Y, Shen YQ, Li YL, Liang C, Zhang BJ, Lu SD, He YY, Wang P, Sun QL, Jin YX, et al: Direct repression of the oncogene CDK4 by the tumor suppressor miR-486-5p in non-small cell lung cancer. Oncotarget 7: 34011-34021, 2016.

38. Xiao P and Liu WL: MiR-142-3p functions as a potential tumor suppressor directly targeting HMGB1 in non-small-cell lung carcinoma. Int J Clin Exp Pathol 8: 10800-10807, 2015.

39. Chen Q, Hu H, Jiao D, Yan J, Xu W, Tang X, Chen J and Wang J: miR-126-3p and miR-451a correlate with clinicopathological features of lung adenocarcinoma: The underlying molecular mechanisms. Oncol Rep 36: 909-917, 2016.

40. Mathew LK, Lee SS, Skuli N, Rao S, Keith B, Nathanson KL, Lal P and Simon MC: Restricted expression of miR-30c-2-3p and miR-30a-3p in clear cell renal cell carcinomas enhances HIF $2 \alpha$ activity. Cancer Discov 4: 53-60, 2014.

41. Rodríguez-González FG, Sieuwerts AM, Smid M, Look MP, Meijer-van Gelder ME, de Weerd V, Sleijfer S, Martens JW and Foekens JA: MicroRNA-30c expression level is an independent predictor of clinical benefit of endocrine therapy in advanced estrogen receptor positive breast cancer. Breast Cancer Res Treat 127: 43-51, 2011.

42. Shin K, Kim KH, Yoon MS, Suh DS, Lee JY, Kim A and Eo W: Expression of interactive genes associated with apoptosis and their prognostic value for ovarian serous adenocarcinoma. Adv Clin Exp Med 25: 513-521, 2016. 